\title{
Sequential analysis of global gene expression profiles in immature and in vitro matured bovine oocytes: potential molecular markers of oocyte maturation
}

\author{
Solomon Mamo ${ }^{1 *}$, Fiona Carter ${ }^{1}$, Patrick Lonergan¹, Cláudia LV Leal ${ }^{1,2}$, Abdullah Al Naib ${ }^{1}$ Paul McGettigan ${ }^{1}$,
} Jai P Mehta', Alexander CO Evans' ${ }^{1}$, Trudee Fair ${ }^{1}$

\begin{abstract}
Background: Without intensive selection, the majority of bovine oocytes submitted to in vitro embryo production (IVP) fail to develop to the blastocyst stage. This is attributed partly to their maturation status and competences. Using the Affymetrix GeneChip Bovine Genome Array, global mRNA expression analysis of immature (GV) and in vitro matured (IVM) bovine oocytes was carried out to characterize the transcriptome of bovine oocytes and then use a variety of approaches to determine whether the observed transcriptional changes during IVM was real or an artifact of the techniques used during analysis.
\end{abstract}

Results: 8489 transcripts were detected across the two oocyte groups, of which $~ 25.0 \%$ (2117 transcripts) were differentially expressed ( $p<0.001$ ); corresponding to 589 over-expressed and 1528 under-expressed transcripts in the IVM oocytes compared to their immature counterparts. Over expression of transcripts by IVM oocytes is particularly interesting, therefore, a variety of approaches were employed to determine whether the observed transcriptional changes during IVM were real or an artifact of the techniques used during analysis, including the analysis of transcript abundance in oocytes in vitro matured in the presence of $\alpha$-amanitin. Subsets of the differentially expressed genes were also validated by quantitative real-time PCR (qPCR) and the gene expression data was classified according to gene ontology and pathway enrichment. Numerous cell cycle linked (CDC2, CDK5, CDK8, HSPA2, MAPK14, TXNL4B), molecular transport (STX5, STX17, SEC22A, SEC22B), and differentiation (NACA) related genes were found to be among the several over-expressed transcripts in GV oocytes compared to the matured counterparts, while ANXA1, PLAU, STCland LUM were among the over-expressed genes after oocyte maturation.

Conclusion: Using sequential experiments, we have shown and confirmed transcriptional changes during oocyte maturation. This dataset provides a unique reference resource for studies concerned with the molecular mechanisms controlling oocyte meiotic maturation in cattle, addresses the existing conflicting issue of transcription during meiotic maturation and contributes to the global goal of improving assisted reproductive technology.

\section{Background}

Transition from the maternal to -embryonic genome control of development occurs relatively late in cattle, during the fourth cell cycle [1]. Thus, the oocyte is the main driver of early embryo development, drawing on maternal mRNAs and proteins accumulated during the

\footnotetext{
* Correspondence: solomon.mamo@ucd.ie

'School of Agriculture, Food Science and Veterinary Medicine, College of Life Science, University College Dublin, Dublin 4, Ireland

Full list of author information is available at the end of the article
}

oocyte growth phase $[2,3]$. In order to achieve a developmentally competent status, the oocyte has to gradually undergo a number of physiological changes that include physical and molecular remodeling [4]. During fetal life, mammalian oocytes initiate meiosis and become arrested at the diplotene stage of prophase I (dictyate stage). The ability of these oocytes to resume meiosis and to complete the first meiotic division is acquired sequentially during their growth phase [5]. In fully grown oocytes, meiotic resumption and nuclear
C Biomed Central 
maturation, in response to the preovulatory gonadotrophin surge in vivo or release from the follicle in vitro, is characterized by germinal vesicle breakdown (GVBD), chromosomal condensation, cumulus cell expansion, hyaluronic acid and cyclic AMP production [5-8], and progression through metaphase I to anaphase and telophase, with extrusion of the first polar body and arrest at metaphase II (MII) until reactivation at fertilization. The basic molecular machinery governing these developmental processes is relatively well conserved across mammalian species $[9,10]$; however, there is a clear difference in the timing of these processes between species (reviewed in [11,12]).

The origin of the oocyte and more specifically, the environment in which oocyte growth and maturation occur [13-17] has been implicated as an important determinant of the subsequent developmental competence of the oocyte. Transcriptional profiling of in vivo and in vitro matured (IVM) oocytes in cattle [18-20], humans [21], and rhesus monkeys [22] have shown variations in a number of genes and distinct pathways, which may have consequential effects during the post fertilization development. For example during the process of in vitro embryo development, while maturation and fertilization proceed apparently normally (based on first polar body extrusion and mitotic cleavage, respectively), the proportion of embryos reaching the transferable (blastocyst) stage rarely exceeds 40 to $50 \%$ and those that do reach this stage are often compromised in quality and further developmental competence [23], an effect partly attributed to inadequate oocyte cytoplasmic maturation $[24,25]$. In contrast, fertilization and culture in vitro of oocytes matured in vivo results in high rates of blastocyst development $[15,26]$ providing further evidence of the importance of oocyte quality in determining developmental competence.

To date, efforts to characterize developmentally competent oocytes have been hampered partly by the difficulty in assessing cytoplasmic maturation [27], and the small volume of material available for analysis. Currently, while nuclear maturation can be assessed by the extrusion of the first polar body and the formation of the second metaphase plate, there is no reliable assay for the assessment of oocyte cytoplasmic maturation, other than the development of the fertilized oocyte to a live offspring $[24,27,28]$. This lack of oocyte quality markers has led some researchers to use embryo morphology or blastocyst rate as alternative early quality predictors of developmental competence [29-31]. Until the mechanisms involved in establishing oocyte quality are elucidated, any effort to use assisted reproductive technologies in the treatment of human infertility or in animal production will be inefficient [28]. Analysis of the oocyte transcriptome during maturation using global
mRNA analysis techniques provides a resource that can be mined and expanded continuously with new software and sequencing techniques to identify genes involved in the processes of meiotic and cytoplasmic oocyte maturation and the specific checkpoints regulating acquisition of full competence [32].

It is well understood that mRNAs stored during the oocyte growth phase are systematically, and in a stepwise manner, degraded or translated to form proteins that regulate subsequent developmental processes $[33,34]$. As a result, down regulation of stored transcripts during oocyte maturation is believed to occur. Although GV intact oocytes show some transcriptional activity $[4,35]$, there are conflicting reports on the occurrence of transcription following the resumption of oocyte meiotic maturation. Comparison of immature (germinal vesicle stage, GV) and in vivo matured oocytes in mice [36], and in humans [32] indicated up regulation of a number of transcripts during oocyte maturation. However, other studies comparing immature and in vitro matured (IVM) oocytes in cattle [37] and in mice [38] reported the absence of over-expressed transcripts during oocyte maturation. Given these apparently conflicting observations, and the opportunity to benefit from the increased coverage (more than 92\%) of the bovine genome sequence [39], we examined transcriptional activities during bovine oocyte maturation and present a dataset that provides a unique reference resource for studies concerned with the molecular mechanisms controlling oocyte meiotic maturation in cattle. These data have been superficially referred to in a previous review paper [2] but a thorough analysis of the gene lists and associated ontologies has not yet been published.

\section{Results}

\section{Experiment 1 Global oocyte transcriptome analysis revealed differentially regulated transcripts}

The hybridized slides were scanned and MIAME-compliant (FGED; http://www.mged.org) gene expression data have been submitted to the Gene Expression Omnibus (GEO) database (GSE23449).

The established Affymetrix linear amplification procedures using the GeneChip ${ }^{\circledR}$ Expression 3'-Amplification Two-Cycle cDNA Synthesis kit yielded closely similar profiles between the five replicates of the same treatment (Pearson's correlation coefficients of the range 0.914 to 0.949 ), indicating a highly reproducible procedure. Moreover, hierarchical clustering and principal component analysis revealed sufficient differences between the transcriptomes of immature and IVM oocytes that allowed them to cluster separately into two groups based on maturation status with a high degree of reproducibility and small variability between samples of 
each treatment (Additional file 1, Figure S1 and Additional file 2, Figures S2A and S2B). The first principal component (PCA1) accounts for $95.12 \%$ of the variability.

By comparing multiple probes matching a target mRNA and evaluating the signal-to-noise ratio, the FARMS http://www-stat.stanford.edu/ tibs/SAM/sam. pdf microarray processing algorithm detected a total of 9178 informative Bos taurus probes corresponding to 8489 annotated genes. 2117 transcripts were found to be differentially expressed between immature and IVM oocytes, corresponding to 1528 transcripts that were significantly lower and 589 that were significantly higher in abundance in IVM oocytes compared to their immature counterparts. The list of differentially expressed transcripts was further analyzed using the DAVID Bioinformatic Resource http://david.abcc.ncifcrf.gov/home.jsp and was found to correspond to 1836 annotated transcripts with NCBI Entrez-Gene IDs, of which 1413 were under-expressed and 423 were over-expressed in the IVM oocytes. The summary and details of differentially expressed transcripts are described in Table 1, Additional file 3, Table S1 and Additional file 4, Table S2. Transcripts were classified according to their gene ontology (GO): molecular function, cellular component and biological process, and the results of overrepresentation analysis are presented in Figure 1.

Biological processes enriched with differentially regulated genes included regulation of various cellular processes, cell communication and intracellular transport, metabolism and translational regulation (Figure 1a and 1b). The majority of over expressed transcripts were associated with cell communication and various cellular processes including homeostasis (Figure 1a) while the metabolic and intracellular transport processes (Figure 1b) were primarily enriched by transcripts which were under expressed in IVM oocytes. This finding is supported by the results of an earlier study in mouse which showed that chemical inhibition of some metabolic pathways induced oocyte maturation [40]. Pathway analysis of the differentially expressed genes using the Ingenuity Pathway Analysis tool detected five major

Table 1 Summary of the global oocyte transcriptome analysis showing the differentially regulated transcripts during bovine oocyte maturation

\begin{tabular}{llll}
\hline Category & Probe sets & Transcripts & $\begin{array}{l}\text { Unique annotated } \\
\text { Transcripts }\end{array}$ \\
\hline $\begin{array}{l}\text { Oocyte } \\
\text { Transcriptome }\end{array}$ & 9178 & 8489 & 6586 \\
$\begin{array}{l}\text { Differentailly } \\
\text { expressed }\end{array}$ & 2244 & 2117 & 1836 \\
$\begin{array}{l}\text { Increased in MII } \\
\text { Increased in GV }\end{array}$ & 613 & 589 & 423 \\
\hline
\end{tabular}

networks, preferentially populated with genes that have important biological functions relevant to development, including cellular growth and development, Molecular transport, Protein synthesis and embryo development (Table 2). Moreover, the detected networks were supportive of the above listed $\mathrm{GO}$ results.

\section{Experiment 2 Quantitative PCR (qPCR) validation of microarray results}

A panel of 25 differentially expressed genes mostly associated with cell cycle functions, and a reference gene (H2AFZ) (Table 3) was selected for validation in independently prepared immature and IVM oocyte samples using qPCR. All but one of the genes $(24 / 25)$ showed a similar expression pattern to the microarray data and 22 of the 25 genes were significantly differentially expressed $(\mathrm{P}<0.05)$ (Figures 2 and 3$)$.

\section{Experiment 3 Effect of $\alpha$-amanitin on transcript abundances}

$\alpha$-amanitin is known as a transcription inhibitor and used in various oocyte and embryo development studies $[41,42]$. Following incubation with the transcription inhibitor, $\alpha$-amanitin, the expression of selected genes over-expressed in the microarray analysis (LUM, MX1, SERPINA14, STC1, PLAU, SERPINE1, and RBP1) was analyzed with qPCR, and transcript abundances were compared. Treatment with $\alpha$-amanitin for either 21 or $24 \mathrm{~h}$ significantly reduced transcript abundances for all genes studied, compared to oocytes matured for $24 \mathrm{~h}$ in the absence of the inhibitor (Figure 4). Furthermore, for many of the transcripts analyzed, the expression profile of the $\alpha$-amanitin-treated oocytes was similar to that of the immature oocytes.

\section{Experiment 4 Effects of analysis parameters on the transcript abundances \\ $4 a$ Contribution of RNA conversion methods to differential expression data}

The aim of this experiment was to examine whether the primers used during cDNA synthesis have contributed to the conflicting data on transcription during mammalian oocyte maturation. Primers used during the reverse transcription reaction are known to influence the cDNA quality and yield. Unlike random primers, oligo (dT) primers tend to show a bias towards the 3' end of transcripts with poly (A) tails. In order to investigate the effect of the primer used during cDNA synthesis on qPCR analysis data, we compared the transcript abundances of a panel of genes in two cDNA preparations obtained from reverse transcription using either random or oligo (dT)-based primers. The transcripts were quantified and normalized to the quantity of an exogenous reference (luciferase), and reported as fold change 


\section{A. Biological process}
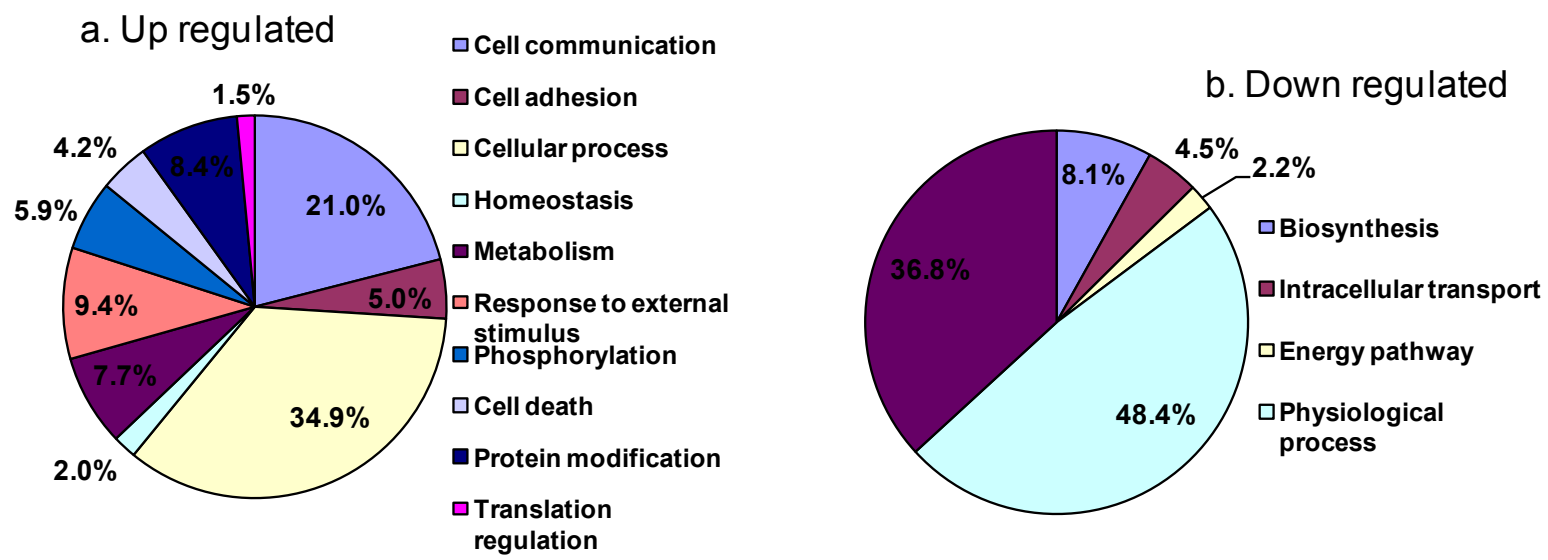

\section{B. Molecular functions}

c. Up regulated

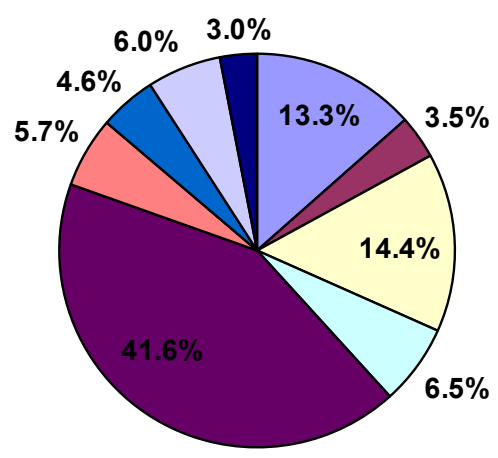

๑ Signal transducer

- Cell adhesion

$\square$ Hydrolase

口Receptor

- Binding

$\square$ Protein kinase

口 Peptidase

口Enzyme regualtor

- Receptor signalling

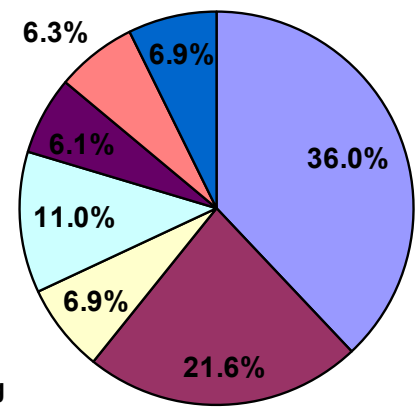

d. Down regulated

\section{Cellular component}

\section{e. Up regulated}

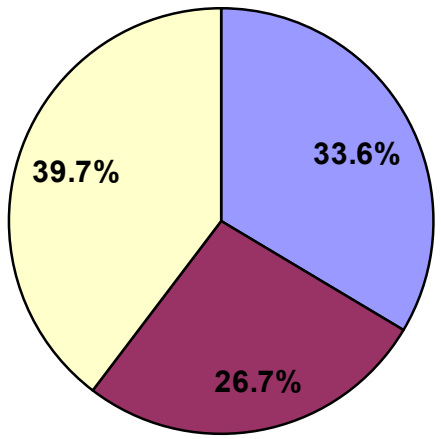

口Extracellular

口Plasma membrane

ulntegral to membrane

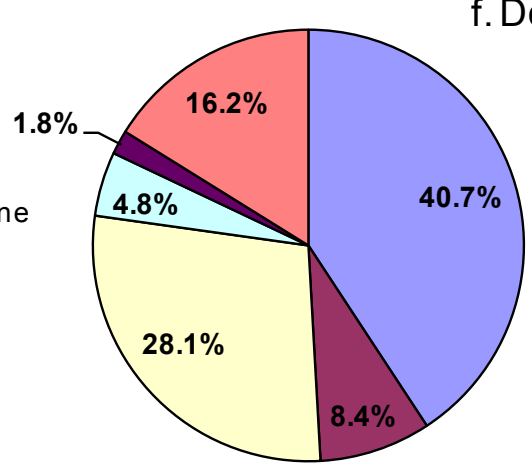

口Binding

$\square$ Transporter

口Structural constituent

口Oxido reductase

口Ion transporter

口Electron transport

口Protein transport

Figure 1 Classification of the differentially expressed transcripts based on gene ontology. (A) Biological process (a and b); (B) Molecular functions ( $c$ and d); and (C) Cellular components (e and f).

differences relative to the immature oocyte transcript abundance.

Generally for an equal quantity of cDNA input, transcripts of the same gene were more abundant in randomprimed cDNA preparations compared to oligo (dT)- primed preparations, as manifested by an earlier Cq value for the former compared to the latter. The expression patterns were similar for both random- or oligo $(\mathrm{dT})$ based priming. However, the calculated ratios for the oligo (dT)- primed cDNA showed a tendency for higher 
Table 2 Top network functions detected during Ingenuity Pathway Analysis

\begin{tabular}{lc}
\hline Associated Network Functions & Score \\
\hline $\begin{array}{l}\text { 1. Cellular assembly and organization, Molecular transport, } \\
\text { Protein Trafficking }\end{array}$ & 42 \\
$\begin{array}{l}\text { 2. Protein synthesis, Cellular function and Maintenance, Small } \\
\text { molecule Biochemistry }\end{array}$ & 35 \\
$\begin{array}{l}\text { 3. Post-Translational Modification, Developmental Disorder, } \\
\text { Embryonic Development }\end{array}$ & 35 \\
$\begin{array}{l}\text { 4. Genetic disorder, neurological disease, Cell-to-Cell Signalling } \\
\text { and interaction }\end{array}$ & 35 \\
5. Cancer, Neurological disease, Renal and Urological Disease & 35 \\
\hline
\end{tabular}

fold change differences for most genes compared to the random hexamer primed cDNA, but differences were not significant (Additional file 5, Figure S3). Moreover, there was no significant difference in the results generated by the use of primers for longer amplicons (Table 4) compared to those for shorter amplicons (Table 3), indicating no bias due to product size in the current study.

$4 b$ Chronological analysis of candidate gene abundance during in vitro oocyte maturation

To avoid the possibility of preferential amplification due to poly (A) tail length, we standardized the cDNA synthesis procedures by using random primers that can account for transcript abundances, irrespective of the poly (A) tail status.

In order to characterize in more detail the chronology of the divergence in transcript abundance between immature and IVM oocytes, oocytes were collected at 0 (GV), 3, 6, 12 and 24 (MII) h after initiation of IVM. The expression profiles of the over-expressed transcripts across the $24 \mathrm{~h}$ maturation window are presented in Figure 5. The relative abundance of four genes (MAOA, STC1, SERPINE1 and PLAT) was significantly ( $<<0.05)$ reduced after $3 \mathrm{~h}$ maturation and gradually increased thereafter to peak either at $12 \mathrm{~h}$ (STC1 and SERPINE1) or $24 \mathrm{~h}$ (PLAT and MAOA). The expression levels of (ANXA1, PLAU and LUM) did not change after $3 \mathrm{~h}$ maturation, but increased thereafter to peak significantly $(\mathrm{p}<0.05)$ at $12 \mathrm{~h}(A N X A 1$ and $P L A U)$ or $24 \mathrm{~h}(L U M)$. The results also indicated that expression levels of $S E R$ PINE1, STC1, PLAU, and ANXA1) were peaked at $12 \mathrm{~h}$ post initiation of IVM and values were significantly $(\mathrm{p}<$ 0.05) higher than those observed at all other time points. Although abundance of these transcripts tended to increase in $24 \mathrm{~h}$ IVM oocytes, compared to $0 \mathrm{~h}$, only expression of LUM and STC1 were significantly higher

Table 3 Sequences and GenBank accession numbers of primers used for qPCR analysis during experiment 2 and 3

\begin{tabular}{|c|c|c|c|c|}
\hline Gene & Forward 5'-3' & Reverse $5^{\prime}-3^{\prime}$ & Product size (bp) & GenBank \\
\hline$\overline{A N X A 1}$ & GAGGAAGTTGTTTGGCTCTATTGA & TGGCAGCACGGAGCTCTT & 67 & NM_175784 \\
\hline CDK1 & TGGACAGTCAAATTAAGAAGATGTAGCT & GTACAATTATCTGCTCTTGACACAACAC & 72 & NM_174016 \\
\hline CDK5 & CCTGCTCATCAACAGGAATGG & AAA GGC GCG AGC CAAAC & 61 & NM_174017 \\
\hline CDK8 & CCCAGCAGCCTCCACAGTA & TGT CCG ACG CAG CTC AGT AC & 57 & XM_583707 \\
\hline CHMP1A & CAGCCCTGGGACTCTTCTTCT & ACTCACCCTGTAGGGCACAGA & 62 & NM_001037584 \\
\hline$H 2 A F Z$ & TCCGGAAAGGCCAAGACA & GAACTGCAAACCGGCTCTCT & 57 & NM_174809 \\
\hline HSPA2 & AGAACCAGGTGGCCATGAAC & TCCGACCAATCAGCCTCTTG & 63 & NM_174344 \\
\hline LUM & TTCAAAGCATTCGCCAAAATG & CCGCCAATTAATGCCAAGAG & 62 & NM_173934 \\
\hline MAD2L2 & GTCTACCCGGTGGGCATCT & CAT CTG GAC AGG CAC GTT GT & 57 & NM_001045946 \\
\hline$M A O A$ & GGGCCAGATGTTCGACGTAGT & AGCTAAGAGTTTCGCAGCAGATAA & 69 & NM_181014 \\
\hline MAPK14 & GCT GTC GAC CTG CTG GAG AAG ATG & TCG TCG TCA GGA TCG TGG TAC TGG & 110 & NM_001102 \\
\hline MLHI & TCCGGGAGATGCTGCATAA & CAA GGC CCA CTG AGG ATT CA & 59 & NM_001075994 \\
\hline$M \times 1$ & GAGCAGTATGACTCCCGACTGTTT & TTCTCAACCACAGCACTCCATTT & 71 & NM_173940 \\
\hline NUDC & CCCCAGATCAAAGAACTGACTGA & GGC ATC CTT TIT CTG GTC AATT & 72 & NM_001075607 \\
\hline PLAU & CGCCACACACTGCTTCATTG & GCCGTGACTGACCCAAGTAGAC & 68 & NM_174147 \\
\hline PPPЗCA & CCTCATCCATACTGGCTTCC & AATCCATCTTCTTCTGACCC & 140 & NM_174787 \\
\hline RBP1 & TGCGCGCGCTGGAT & GCTTCAGCAAGTTGGCGATT & 54 & NM_001025343 \\
\hline SERPINE1 & GGACTTCTCCAGTIITICAGATCAAG & CAGCGTGCCGCTCTCATT & 91 & NM_174137 \\
\hline SERPINA14 & ACCCTGAGGACCTGAAACTTGAG & CGTGGACCAGAGGCTGTAAGTACT & 69 & NM_174797 \\
\hline SIPA1 & GCCCATTATTCGGTGACACAGT & GAAGTCCCCTITTCTCCACAGA & 72 & NM_001101895 \\
\hline SSSCA1 & TGACTGCGGGACGATCCT & TGA CAA GCC ACG CAG TAG ATT T & 60 & NM_001038528 \\
\hline STC1 & TITGCAATGGCGGCATT & TCCCGAGGAGAGGCATAGAG & 60 & NM_176669 \\
\hline TFDP2 & GGTGCCACCTTGTCCCAAT & CTA AGG CCA CTT CAG CAT CCA & 64 & NM_001075241 \\
\hline TGFB2 & TCTCCAACCCAGCGCTACA & TTCACCCTCTGCTCTGGTITC & 57 & NM_001113252 \\
\hline TSC2 & CAGAGGGCAAACAGACTGAGTTTAT & GCG ATT ATT GAG GCC ACA TTC & 80 & XM_581197 \\
\hline$T X N L 4 B$ & TGGTAATCGTGATGCATGGAA & GGC TGG TTG CCT CAT GGT & 58 & NM_001014897 \\
\hline
\end{tabular}




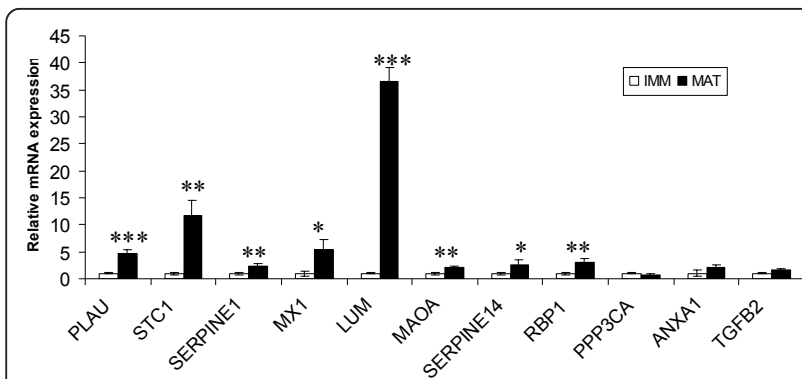

Figure 2 qPCR analysis of selected genes from the list of overexpressed transcripts. Expression of MII oocytes (black bars) was compared to GV oocytes (white bars). All expression levels are relative to the level of expression in GV oocytes (white bars) which has been arbitrarily set to one-fold. Stars denote statistical difference ${ }^{*}=p<0.05,{ }^{* *}=p<0.01,{ }^{* * *}=p<0.001$

( $\mathrm{p}<0.05)$. In general, the expression levels observed at $24 \mathrm{~h}$ were similar (but not identical) with the earlier profile for the same gene at this time point following normalization using luciferase. This similarity reinforced our approach to use validated reference genes for this and other subsequent experiments.

\section{4c Candidate gene expression in oocytes matured in vivo}

The aim of this experiment was to verify if the gene expression changes observed in the IVM oocytes (Experiment $4 \mathrm{~b}$ above) are also observed in oocytes matured in vivo.

The expression profiles of five transcripts ( $L U M$, PLAT, SERPINE1, STC1 and PLAU) that were overexpressed in oocytes matured in vitro were quantified in in vivo derived bovine oocytes. The results revealed a similar tendency of increased abundance after maturation for all examined genes (PLAT, SERPINE1, STC1 and $P L A U)$; the differences were significant in the case of STC1 $(p<0.01)$ and LUM $(p<0.00001)$ (Figure 6). The significant over-expression of these genes (STC1 and LUM) in mature oocytes was similarly noted in in

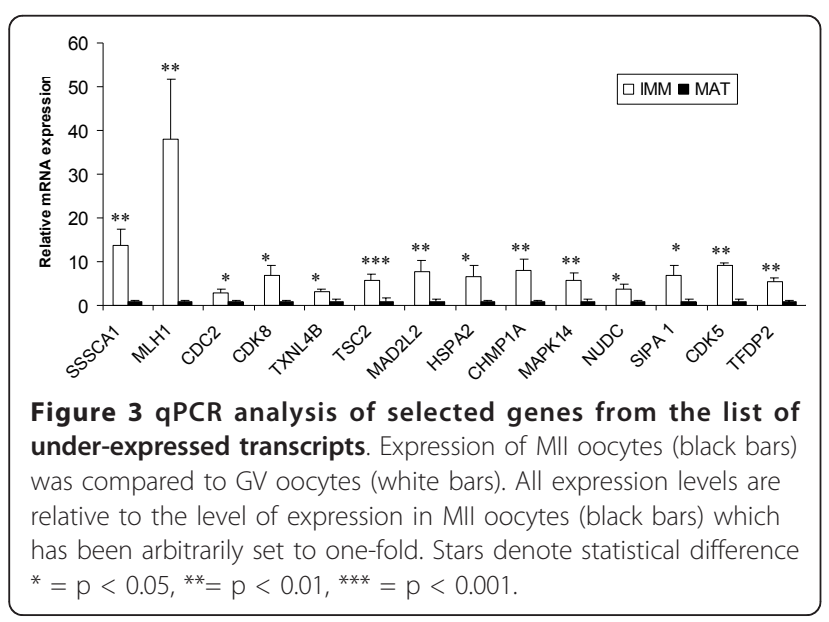

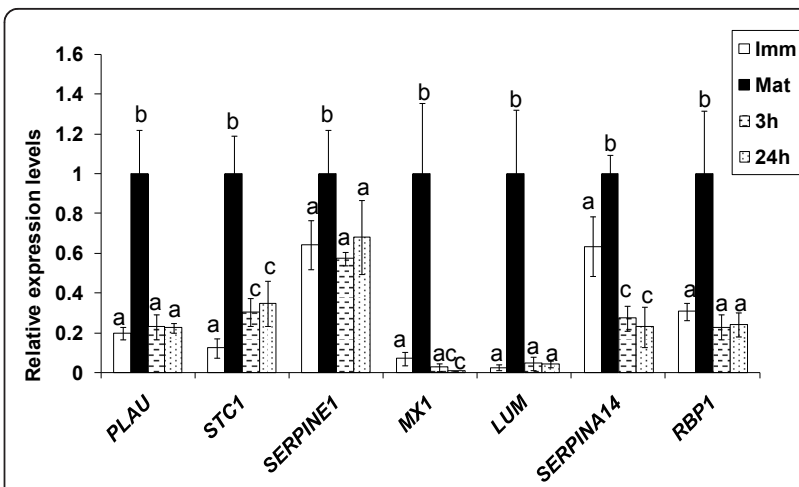

Figure 4 Relative abundance of specific transcripts in bovine oocyte matured with or without $\alpha$-amanitin. The figure shows GV (white), MII (black), MII oocytes matured in the presence of $\alpha^{-}$ amanitin after $3 \mathrm{hr}$ of culture (line spotted), MII oocytes matured in $\alpha$-amanitin for $24 \mathrm{hr}$ (dot spotted). All expression levels are relative to the level of expression in MII oocytes (black bars) which has been arbitrarily set to one-fold.

vitro samples (Figure 5). Due to the negligible expression of LUM in immature oocytes an arbitrary Cq value of 40 was assigned for the expression in immature oocytes, in order to calculate the relative abundances.

\section{Discussion}

The issue of transcript regulation during oocyte maturation is a controversial topic in developmental biology. Various previous efforts [32,36-38] to decipher the transcriptional changes during oocyte maturation have been masked by contradictory outcomes. In the current study, we established the global changes in transcriptomic profile during meiotic maturation in bovine oocytes. Moreover, in an effort to examine the possible sources of conflicting reports, we further investigated transcription in the presence of transcription inhibitor, effects of primers, amplified product sizes, reference genes and sample types (in vitro and in vitro) on transcript abundance. Here we (1) report the existence of transcription activities during bovine oocyte maturation, (2) show suppression of over-expressed genes when oocytes were matured in the presence of an inhibitor of transcription suggesting that the observed transcript changes were newly synthesized, (3) report that the new transcription was not sample type (in vitro or in vivo) -specific, (4) report primers used during cDNA synthesis and reference genes used for normalization have an impact on the interpretation of the gene expression data, but not the amplified product sizes.

The genome-wide interrogation of immature and in vitro matured bovine oocytes on the Affymetrix GeneChip bovine array identified a number of differentially expressed genes, the vast majority $(\sim 75 \%)$ of which were over-expressed in immature oocytes (Table 1). It is well 
Table 4 Sequences and GenBank accession numbers of re-designed primers used for qPCR analysis during experiment 4

\begin{tabular}{|c|c|c|c|c|}
\hline Gene & Forward 5'-3' & Reverse $5^{\prime}-3^{\prime}$ & Product size (bp) & GenBank \\
\hline$\overline{A N X A 1}$ & ATGGTATCTGAATTCCTCAAGCAG & TGCAAGGCCTCAACATCC & 149 & NM_175784 \\
\hline HZAFZ & CGGAAAGGCCAAGACAAAG & CTGAAATCTAGGACGACTAGCCAT & 103 & NM_174809 \\
\hline Luciferase & TCCTCCAGGGATACGACAAG & GGTATCCAGATCCACAACCTTC & 139 & EU684088 \\
\hline LUM & CGAAAGCAGGGTCAAGACAG & TGATGACCTCCCATACAGTGC & 158 & NM_173934 \\
\hline$M A O A$ & TGGCGGACCATGGATAAC & AAACTGCCGAGCAGTCTTTG & 138 & NM_181014 \\
\hline PLAT & TGTGGAGCTGTCTTCACGTC & CGTGTTGGCGGTACGTC & 118 & NM_174146 \\
\hline PLAU & CTGTGCCCTGGTCGTGAG & GCAACTGCATCGCTGAATG & 136 & XM_174147 \\
\hline PPIA & CCACCGTGTTCTTCGACATC & CCAAATCCTITCTCTCCAGTGC & 130 & NM_178320 \\
\hline SDHA & GGGAGGACTTCAAGGAGAGG & TCAACGTAGGAGAGCGTGTG & 112 & NM_174178 \\
\hline SERPINE1 & CAGGCGGACTTCTCCAGTT & CATTCGGGCTGAGACTACAAG & 135 & NM_174137 \\
\hline STC1 & GTGACACAGATGGGATGTACGAC & CGAATGGCCAGGAAGACC & 142 & NM_176669 \\
\hline TGFB2 & AGGCCGAGTTCAGAGTCTITC & TGTAGCGCTGGGTTGGAG & 117 & NM_001113252 \\
\hline YWHAZ & GCAGATGGCTCGAGAATACAG & GAAGCGTTGGGGATCAAG & 102 & NM_174814 \\
\hline
\end{tabular}

accepted that mammalian oocytes have already accumulated the majority of their transcripts at the fully grown immature (GV) stage that will drive subsequent development through degradation, translation and post-transcriptional modifications [33,34] up to embryonic genome activation. Therefore, the observation of a massive reduction of the initial transcript stock in our study was in line with the current understanding of events during oocyte maturation. On the other hand, the detection and confirmation of certain over-expressed transcripts during bovine oocyte maturation suggests the existence of transcription, perhaps to complement the depleting transcriptional stock.

Despite the multiple roles of a particular gene [43], Ingenuity Pathway Analysis classified the differentially regulated genes into various associated functional network groups (Table 2). These include cellular assembly, molecular transport, post-translational modification and cell to cell signaling, all of which occur during oocyte maturation. For example, cell-to-cell signaling between oocytes and their surrounding somatic cells is important for oocyte cytoplasmic maturation and the acquisition of developmental competence. This is a bidirectional communication mediated through the transport of various growth factors, such as GDF9 and BMP15, from oocytes to their surrounding cumulus cells [44-46], and cyclic adenosine monophosphate (cAMP) from somatic cells to the oocyte [47] via gap junctions.

Generally, the sequence of events leading to the GVBD (Germinal Vesicle Breakdown) and the requirements for transcription and/or protein synthesis differs markedly between species $[12,48]$. For example, in frog, mouse, rat and fish oocytes, high levels of cAMP prevent oocyte maturation in vitro, while a decrease in oocyte cAMP is associated with the resumption of meiosis $[49,50]$. In contrast, maturing oocytes from pig, sheep, cattle and rabbit exhibit a transient increase rather than a decrease in cAMP levels, and treatments that increase cAMP levels can induce oocyte maturation [49,51-53]. Similarly, an earlier study [12] confirmed the requirements of transcription and protein synthesis as requirements for GVBD in domestic animals (sheep, cattle and pigs) while neither event is required for the initiation of maturation in mouse oocytes. Generally our finding is in line with earlier studies in bovine [54-56] that observed various over-expressed transcripts during oocyte maturation.

In order to verify if the over-expressed transcripts were transcribed following submission of oocytes to IVM, oocytes were matured in the presence of the RNA polymerase II inhibitor, $\alpha$-amanitin for $24 \mathrm{~h}$. The resulting transcript profile was similar to that of the immature oocytes, which is consistent with the notion that $24 \mathrm{~h}$ exposure to $\alpha$-amanitin prevents meiotic resumption in most oocytes [57]. This study [57] also reported that addition of $\alpha$-amanitin after $3 \mathrm{~h}$ of culture had no effect on meiotic maturation. However, in the current study exposure of the oocytes to the $\alpha$-amanitin treatment following an initial $3 \mathrm{~h}$ culture in $\alpha$-amanitin-free medium resulted in a similar level of expression to that observed when the inhibitor was present throughout. These findings suggest that some de novo transcription is occurring in bovine oocytes following the resumption of meiosis.

In order to examine the contributions of some downstream analysis procedures on the final transcript data, we further examined the implications of primer choices during cDNA synthesis. Although not significant, there was a tendency for higher expression fold change (ratio) for oligo (dT)-based cDNA preparations compared to random-based cDNAs. This suggests the preferential amplification of oligo (dT)-based primers, and the 

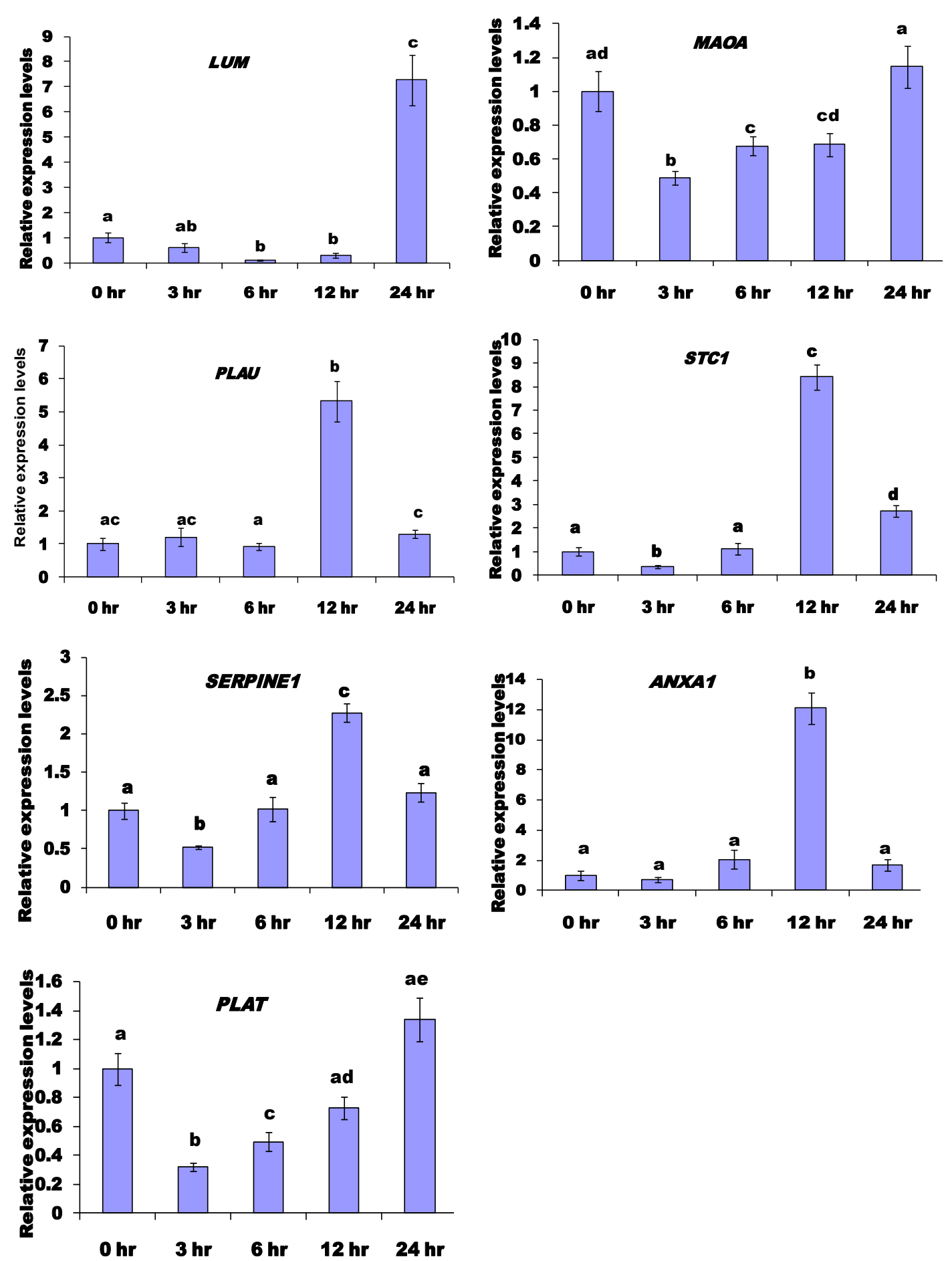

Figure 5 Relative gene expression profiles of in vitro mature bovine oocytes at different time points. In all cases the expression at time 0 $\mathrm{h}$ was taken as calibrator against which the relative levels of other time points were calculated. Time points with the same letter are not significantly different $(p<0.05)$. 


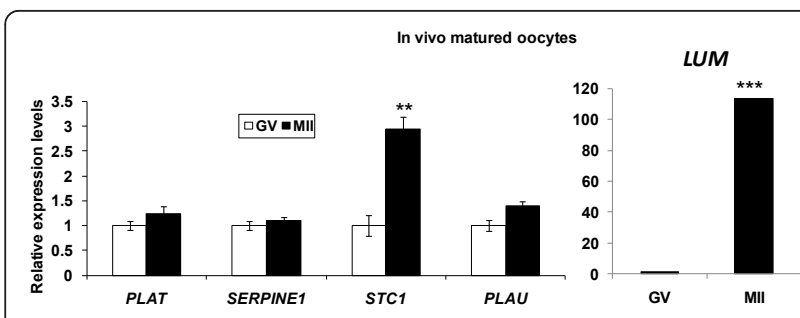

Figure 6 Relative gene expression profiles of bovine oocytes, before (GV) and after (MII) in vivo maturation. In all cases the expression at time immature (GV) stage was taken as calibrator against which the relative levels of other time points were calculated. ${ }^{* *}$ indicates significance $(p<0.01)$ and ${ }^{* *}$ indicates significance $(p<0.0001)$. Due to the insignificant levels of LUM in immature oocytes an arbitrary $40 \mathrm{Cq}$ values were assigned to calculate the relative fold change.

finding is in agreement with most other previous observations [54,58-61], although another study [19] reported an identical results irrespective of the primers used. The fact that anchored oligo (dT) was used in our study may have narrowed the difference. It has been shown previously that anchored oligo $(\mathrm{dT})$ primers are better than the conventional oligo (dT) primers in maintaining the fidelity of the probes, as the latter generates a high frequency of truncated cDNA through internal poly (A) priming [62]. This observation further signifies the contribution of primers to the final conclusions, and the need to select appropriate primers commensurate with the sample type for analysis. Therefore, it is possible to speculate that this may have also contributed to the earlier contradictory reports on the occurrence of transcription during meiotic maturation [32,36-38].

Increasing stringency by controlling primers for cDNA synthesis, designing intron-spanning primers for amplification and the use of alternative validated reference genes during the analysis appears to reduce the number of significant genes at $24 \mathrm{~h}$. Interestingly, when we analysed the kinetics of transcript expression during maturation the abundance of several transcripts was significantly higher at $12 \mathrm{~h}$ compared to $0 \mathrm{~h}$. The kinetics of bovine oocyte maturation has been well described [63-66]. In most oocytes GVBD occurs between 4 and 8 $\mathrm{h}$ after initiation of maturation, and has occurred in the majority of oocytes by $8 \mathrm{~h}$. By $12 \mathrm{~h}$ the majority of oocytes have reached metaphase I. Progression from GVBD through the subsequent stages of meiosis is under the control of the anaphase promoting complex (APC) which is mainly regulated through sequential polyadenylation and deadenylation of transcripts [67] and the increased abundance of these transcripts at this time may reflect their association with APC. These genes are implicated in various developmental activities including cell signaling, apoptosis and membrane trafficking (ANXA1) [68], and cumulus cell expansion $(P L A U)$ (reviewed in [55]).

Irrespective of the introduction of increased stringency measures, the abundance of STC1 and LUM was significantly higher in both in vivo and in vitro matured oocytes compared to $0 \mathrm{~h}$ (GV stage oocytes) (Figure 5 and Figure 6). Furthermore, transcript abundances were maintained at $0 \mathrm{~h}$ levels when oocytes were matured in the presence of $\alpha$-amanitin. Taken together, these findings strongly suggest de novo transcription of STC1 and LUM following the resumption of meiosis. Analysis of various studies suggests STC1 has effects on metabolism, reproduction, and developmental processes in addition to affecting mineral homeostasis (reviewed in [69]. STC1 expression was highest in mouse ovary, with lower but detectable levels in most other tissues [70]. Based on this result and the initial implication of the gene in mineral metabolism, it was suggested that STC1 may have acquired an important function in reproduction during its evolution in mammals [70]. Similarly, increasing evidence suggests that LUM may also serve as a regulatory molecule of several cellular functions [71,72]. Previous study in mice using Northern and In situ hybridization indicated that, in early stages of embryonic development before day 7 post-coitus, the embryo does not express LUM or expresses only very low amounts [73]. This is the first study to examine and reveal the expression of these two genes (LUM and STC1) during oocyte maturation. Based on the consistent expression pattern in repeated experiments of in vitro and in vivo derived oocytes, it is plausible to speculate that these two genes (LUM and STC1) may be potential molecular markers of oocyte maturation and may contribute to the early events of embryo development.

\section{Conclusions}

We have used global microarray analysis to establish the molecular transcriptome blueprint of immature and matured oocytes and to identify and validate genes that are unique to and predominantly expressed in bovine immature and IVM oocytes. The genes identified will be invaluable in further studies examining the processes of oocyte maturation in addition to addressing the existing conflicting issue of transcription during meiotic maturation. Moreover, it will enable the comparisons across many species and contributes to the goal of improving assisted reproductive technology.

\section{Methods}

All chemicals, unless stated otherwise, were purchased from Sigma-Aldrich Chemical Inc. (St. Louis, MO, USA). All experimental procedures involving animals were licensed by the Department of Health and 
Children, Ireland, in accordance with the Cruelty to Animals Act (Ireland 1897) and the European Community Directive $86 / 609 / \mathrm{EC}$ and were sanctioned by the Animal Research Ethics Committee of University College Dublin. Four experiments each with different objectives and methodologies were carried out, as described separately in the result sections.

\section{Collection of immature and in vitro matured oocytes}

Immature cumulus oocyte complexes (COCs) were obtained by aspirating 3 to $8 \mathrm{~mm}$ follicles on the ovaries collected from cows slaughtered at a local abattoir. Good quality COCs, judged morphologically with multiple cumulus layers and homogenous cytoplasm, were selected under the stereo microscope and washed repeatedly in modified phosphate-buffered saline (PBS, supplemented with $36 \mathrm{mg} \mathrm{mL}^{-1}$ pyruvate, $50 \mathrm{mg} \mathrm{mL}^{-1}$ gentamycin, and $0.5 \mathrm{mg} \mathrm{mL}^{-1}$ bovine serum albumin fraction V). Following washing, half of the COCs were immediately denuded by repeated pippeting in PBS. After carefully evaluating the oocytes under a stereomicroscope, intact oocytes with no cumulus traces were pooled in groups of 10 oocytes per tube and immediately snap frozen in liquid nitrogen. The remaining half COCs were incubated in maturation medium [TCM-199 supplemented with $10 \%(\mathrm{v} / \mathrm{v})$ fetal calf serum and 10 $\mathrm{ng} / \mathrm{ml}$ epidermal growth factor] in 4-well dishes (Nunc, Roskilde, Denmark) at $39^{\circ} \mathrm{C}$ for $24 \mathrm{~h}$ under an atmosphere of $5 \% \mathrm{CO}_{2}$ in air with maximum humidity. At 24 $\mathrm{h}$, in vitro matured (IVM) COCs were denuded and snap frozen as described above. Five replicates (= days of ovary collection) were carried out, and all samples were stored at $-80^{\circ} \mathrm{C}$ until analysis.

\section{Collection of immature and in vivo matured oocytes}

The collection of immature and in vivo matured oocytes was carried out as previously described [26,74,75]. Briefly, ten crossbred beef heifers were synchronized using an 8-day CIDR treatment with administration of a prostaglandin F2a analogue (PG), the day before CIDR removal, to ensure complete regression of the corpus luteum. Animals were checked for standing estrus (= Day 0) and starting on Day 10 of the estrous cycle, animals were superovulated with FSH given as twice daily injections over four days. Luteolysis was induced with a second PG injection given on Day 12. To collect immature COCs, five cows were slaughtered $40 \mathrm{~h}$ after PG, equivalent to the expected time of the LH surge, and therefore just before resumption of meiosis. The remaining five cows received $\mathrm{GnRH}$ at $40 \mathrm{~h}$ post PG to induce an LH surge [15,76], and were slaughtered $20 \mathrm{~h}$ later (i.e. $60 \mathrm{~h}$ after PG) to collect in vivo matured COCs. 32 good quality in vivo derived immature and 22 good quality in vivo matured oocytes were collected,
COC's were denuded as described above, snap frozen and stored at $-80^{\circ} \mathrm{C}$ until analysis.

\section{Experiment 1 Microarray analysis of oocyte transcripts a. RNA Extraction, cRNA Preparation, Microarray Hybridization and Processing}

5 replicate pools ( $=$ days of oocyte collection) each of 100 denuded immature and IVM oocytes were processed for Affymetrix GeneChip analysis. Total RNA was extracted simultaneously from all replicate pools of immature and IVM oocytes using the PicoPure RNA Isolation kit (Arcturus Bioscience, Mountain View, CA, USA), by incorporating a DNase treatment step using RNase-free DNase set (Qiagen, West Sussex, UK), according to the manufacturer's instructions. Quality of the extracted total RNA and concentration $(\mathrm{ng} / \mu \mathrm{l})$ were assessed using the Agilent Bioanalyzer 2100 with RNA 6000 Nano Chip kit (Agilent Technologies, Santa Clara, USA) and Quant-iT ${ }^{\mathrm{TM}}$ RiboGreen ${ }^{\circledR}$ RNA assay kit (Invitrogen, Carlsbad, CA), respectively following the manufacturer's instructions. $100 \mathrm{ng}$ of total RNA was subjected to two rounds of linear amplification using the GeneChip ${ }^{\circledR}$ Expression 3'-Amplification Two-Cycle cDNA Synthesis kit (Affymetrix Inc., Santa Clara, CA) according to the manufacturer's instructions. cDNA was synthesized during the first cycle and biotin-labeled nucleotides were incorporated during the second in vitro transcription reaction. The resulting labeled antisense RNA samples were fragmented and $15 \mu \mathrm{g}$ each per array was hybridized to five GeneChip Bovine Genome Arrays (Affymetrix) for $16 \mathrm{~h}$ at $45^{\circ} \mathrm{C}$. Once completed, arrays were processed according to the manufacturer's protocol and scanned using the GeneChip ${ }^{\circledR}$ Scanner 3000 (Affymetrix).

\section{b. Microarray data, Pathway and Gene Ontology Analysis}

The Affymetrix GeneChip Bovine Genome array contains 24,027 probe sets corresponding to approximately 23,000 transcripts including assemblies from $\sim 19,000$ UniGene clusters. The arrays images were first quantified using Gene Chip Operating Software (GCOS, Affymetrix). The Affymetrix CEL files were loaded into an AffyBatch object using R/Bioconductor [77]. The FARMS algorithm with quantile normalization was used to summarize the probes from the arrays [78]. The noninformative probes were excluded using the informative/ non-informative calls from the enhanced-FARMS algorithm [79]. The SAM algorithm [80] with a delta of 0.35 (standard cutoff used by SAM algorithm to determine differentially expressed genes) and a very stringent cutoff with the false discovery rate of 0.0001 were used to identify differentially regulated probe sets between the immature and IVM oocytes. To estimate similarity in gene expression profiles of oocytes at immature and after IVM, samples were subjected to hierarchical 
clustering. The average linkage clustering algorithm was applied to the logged interpretation of the gene list. The confidence levels were calculated using 100 datasets (bootstrapping). Principal Component Analysis (PCA) algorithm was applied to the gene list using GeneSpring Software (Agilent Technologies). Automatic annotation with standard lists was also performed. The expressed differentially regulated genes were classified according to their gene ontology (GO) [81]: Molecular function, Cellular component and Biological process. In order to understand the relationship between the differentially regulated genes and their functional interaction assessment, enrichment of pathway analysis was carried out using DAVID [82,83] and Ingenuity Pathway Analysis (IPA) software http://www.ingenuity.com.

\section{Experiment 2 Validation of microarray data using qPCR}

Four additional replicate pools, each of 10 immature and IVM oocytes were prepared as described above. The mRNA extraction was performed using the Dynabeads ${ }^{\circledR}$ mRNA DIRECT ${ }^{\mathrm{TM}}$ Micro Kit (Invitrogen, Paisley, UK) according to the manufacturer's instructions. Following extraction, cDNA was synthesized in a $40 \mu \mathrm{l}$ reaction volume using SuperScript ${ }^{\circledR}$ III reverse transcriptase kit (Invitrogen) supplemented with $200 \mathrm{ng}$ of random primers (Invitrogen) according to the manufacturer's instructions. The cDNA synthesis reaction conditions were $70^{\circ} \mathrm{C}$ for $5 \mathrm{~min}, 25^{\circ} \mathrm{C}$ for $5 \mathrm{~min}, 50^{\circ} \mathrm{C}$ for $1 \mathrm{~h}$, followed by heat inactivation of the enzyme at $75^{\circ} \mathrm{C}$ for 15 $\min$.

Relative transcript abundance of selected cell cycleassociated genes was assessed by performing qPCR using the ABI Prism 7300 Sequence Detection System (Applied Biosystems Foster City, CA, USA). Primer sequences and product sizes are described in Table 3. Analysis of qPCR was performed in a $25 \mu \mathrm{l}$ reaction volume by adding $1.5 \mu \mathrm{l}$ cDNA ( 0.30 oocyte equivalent) aliquot of each sample to the PCR mix containing gene specific primers and $50 \%$ Power SYBR $^{\circledR}$ Green PCR Master mix (Applied Biosystems). qPCR conditions were $2 \mathrm{~min}$ at $50^{\circ} \mathrm{C}, 10 \mathrm{~min}$ at $95^{\circ} \mathrm{C}, 40$ cycles of $15 \mathrm{~s}$ at $95^{\circ} \mathrm{C}$ and $1 \mathrm{~min}$ at $60^{\circ} \mathrm{C}$ for annealing and extension. At the end of each qPCR reaction, melt curve analysis was performed for all genes to check the specificity of the products. Samples were measured in duplicate for each gene of interest and the reference gene $H 2 A F Z$ [84] was measured in all samples as normalizer.

Quantification of transcript (mRNA expression) levels was carried out by using the comparative quantification cycle (Cq) method (ABI Prism Sequence Detection System, User Bulletin No. 2 (Applied Biosystems) [85]. Normalization was carried out by subtracting the $\mathrm{Cq}$ values of $H 2 A F Z$ from the corresponding $\mathrm{Cq}$ values of the target gene. Following normalization the relative abundance of mRNAs between the two populations was calculated from the expression ratios of immature and IVM oocytes to calculate a fold change value. Statistical analysis of the expression values was carried out using the student's t-test.

\section{Experiment 3 Effect of $\alpha$-amanitin on transcript abundances}

The aim of this experiment was to assess the effect of oocyte IVM in the presence of $\alpha$-amanitin, a transcription inhibitor acting through inhibition of RNA polymerase II $[41,57]$, on transcript abundances. Immature COCs (4 replicates of 200) were collected from slaughterhouse ovaries as described above. On a given day (= replicate) 50 COCs were denuded immediately and snap frozen in pools of 10 . The remaining 150 COCs were randomly divided among the following three treatments in groups of 50: (1) matured in vitro for $24 \mathrm{~h}$ as described above (Control), (2) cultured for $24 \mathrm{~h}$ in IVM medium supplemented with $25 \mu \mathrm{g} / \mathrm{ml} \alpha$-amanitin, and (3) cultured in $\alpha$-amanitin-free IVM medium for $3 \mathrm{~h}$ and then transferred to IVM medium supplemented with $25 \mu \mathrm{g} / \mathrm{ml} \alpha$-amanitin for the remaining $21 \mathrm{~h}$. Concentration of $\alpha$-amanitin and length of culture were based on previous publications [42,57]. After maturation, COCs were denuded of their surrounding cumulus cells, snap frozen in pools of 10 per treatment and stored at $-80^{\circ} \mathrm{C}$ until analysis. RNA extraction, cDNA synthesis and qPCR analysis were carried out as described for Experiment 2 above.

\section{Experiment 4 Effects of analysis procedures on the interpretation of oocyte transcriptional profiles}

As mentioned above, there are conflicting reports in the literature [32,36-38] on oocyte transcription profiles during maturation. The aim of these experiments was to examine the effects of certain transcript analysis procedures on the outcomes of the experiment, and if these contributed to the conflicting conclusions. Specifically we examined (1) the type of primers used during cDNA synthesis (Experiment 4a), (2) the expression profiles of some over-expressed genes in in vitro matured oocytes after normalization with validated reference genes, (Experiment 4b), and (3) the expression profiles of some over-expressed genes in in vivo matured oocytes after normalization with validated reference genes (Experiment 4c). In order to avoid unintentional sources of variations, some modifications were made to the Materials and Methods as described below.

\section{a. RNA isolation and reverse transcription}

Four replicate (day or collection) pools of 10 oocytes were prepared as described above and processed for each developmental stage (immature and IVM oocytes). 
During Experiment 4a, 1 pg/oocyte of luciferase mRNA was added, prior to RNA extraction as an exogenous control. Total RNA was isolated using RNeasy Micro kit (Qiagen) with on-column DNase digestion step using an RNase-Free DNase set (Qiagen), according to the manufacturer's instructions.

During Experiment 4a, the eluted total RNA was mixed well and divided into two equal parts for cDNA synthesis, using either random or anchored oligo (dT) primers (Invitrogen). However, for Experiments $4 \mathrm{~b}$ and $4 \mathrm{c}$, random primers were used during cDNA synthesis. All RNA samples in the same experiment were simultaneously reverse transcribed into cDNA using the SuperScript ${ }^{\circledR}$ III reverse transcriptase kit (Invitrogen), in a final $25-\mu \mathrm{l}$ reaction volume, and reaction conditions described above in Experiment 2. After cDNA synthesis, $1 \mu \mathrm{l}$ of cDNA was taken from each sample as template for PCR amplification to check the reverse transcription success and cDNA quality with primers designed to span intron sequences. This procedure was used as a standard during CDNA synthesis for Experiment 4.

\section{b. Optimization and $q P C R$ analysis}

Subsets of over-expressed genes from the microarray analysis list and reference genes were selected for reanalysis and comparison using qPCR. Bovine sequences for these genes were retrieved from the NCBI Database http://www.ncbi.nlm.nih.gov/ and used to re-design primers that can amplify longer product sizes compared to primers in Experiment 2 and 3, using Primer 3 software http://frodo.wi.mit.edu/primer3/. Intron spanning primer sequences were preferentially selected, and produced as HPSF (High Purity Salt Free) purified primers (MWG Biotech, Ebersberg, Germany). Sources, primer sequences and product sizes are listed in Table 2. Primers were optimized and specificity of amplicons was confirmed by melt curve analysis and fragment sizes were confirmed by agarose gel electrophoresis.

Detection and quantification of the transcripts was assessed following $\mathrm{qPCR}$ procedures. Each $\mathrm{qPCR}$ reaction consisted of $1.5 \mu \mathrm{l} \mathrm{cDNA}$ template (equivalent to 0.30 oocyte), $0.1-0.3 \mu \mathrm{M}$ of each primer and $50 \%$ Power SYBR $^{\circledR}$ GREEN PCR Master mix (Applied Biosystems) in a final $15-\mu$ l reaction volume. Forty five cycles of qPCR was carried out employing the reaction conditions described above. Data were normalized either to the quantity of luciferase (Experiment $4 \mathrm{a}$ ) or to the geometric averages of three endogenous reference genes (PPIA, SDHA, YWHAZ) that were validated in our laboratory (Experiments $4 \mathrm{~b}$ and $4 \mathrm{c}$ ). Quantification was carried out using the relative standard curve method (User Bulletin \#2, ABI Prism 7700 Sequence Detection System) and the results were reported as relative expression levels (fold change) compared to the calibrator (immature oocyte).

\section{Additional material}

Additional file 1: Figure S1: Hierarchical clustering analysis of the less stringent gene list. Gene Spring software was used to analyze similarities among the 10 replicate samples (vertical bars) across the two treatments. Colours correspond to the level of expression of the detected genes each of which is represented by one horizontal bar.

Additional file 2: Figure S2: Data quality control analysis of GV (yellow) and MII (red) array results showing how the expression data of the ten replicates group together based on maturational status using (A) PCA plots and (B) hierarchically clustering.

Additional file 3: Table S1: Transcripts over-expressed in IVM oocytes compared to immature oocytes (GV).

Additional file 4: Table S2: Transcripts under-expressed in IVM oocytes compared to immature oocytes (GV).

Additional file 5: Figure S3: Comparative gene expression profiles of immature and in vitro mature oocytes after total RNA was reverse transcribed with different primers. The total RNA from these samples was reverse transcribed either with (A) random primer or (B) anchored oligo (dT) primers. In all cases, expression at the immature (GV) stage was taken as calibrator and relative expression levels were described as fold change.

\section{Acknowledgements}

Mary Wade is gratefully acknowledged for her excellent technical assistance. Grants

The work was supported by Science Foundation Ireland under Grant Nos. 02/IN1/B78 \& 07/SRC/B1156 (the opinions, findings and conclusions or recommendations expressed in this material are those of the authors and do not necessarily reflect the views of the Science Foundation Ireland).

\section{Author details}

${ }^{1}$ School of Agriculture, Food Science and Veterinary Medicine, College of Life Science, University College Dublin, Dublin 4, Ireland. ${ }^{2}$ Faculdade de Zootecnia e Engenharia de Alimentos, Universidade de São Paulo, Pirassununga-SP, Brazil.

\section{Authors' contributions}

SM, TF, PL and AE designed the experiment. SM and FC performed the experimental work. SM was the primary author of the manuscript with significant contribution from TF and PL. FC, SM, CL and AA collected in vitro oocyte samples for analysis. PM and JPM performed the microarray data analysis. All authors read and approved the manuscript.

Received: 7 December 2010 Accepted: 16 March 2011

Published: 16 March 2011

\section{References}

1. Memili E, First NL: Zygotic and embryonic gene expression in cow: a review of timing and mechanisms of early gene expression as compared with other species. Zygote 2000, 8(1):87-96.

2. Fair T, Carter F, Park S, Evans AC, Lonergan P: Global gene expression analysis during bovine oocyte in vitro maturation. Theriogenology 2007, 68(Suppl 1):S91-97.

3. Hamatani T, Yamada M, Akutsu H, Kuji N, Mochimaru Y, Takano M, Toyoda M, Miyado K, Umezawa A, Yoshimura Y: What can we learn from gene expression profiling of mouse oocytes? Reproduction 2008, 135(5):581-592.

4. Fair T, Hyttel P, Greve T, Boland M: Nucleus structure and transcriptional activity in relation to oocyte diameter in cattle. Mol Reprod Dev 1996, 43(4):503-512.

5. Fair T, Hyttel P, Greve T: Bovine oocyte diameter in relation to maturational competence and transcriptional activity. Mol Reprod Dev 1995, 42(4):437-442.

6. Fenton SE, Dentine MR, Ax RL: Modulation of bovine oocyte-cumulus cell complex maturation and fertilization in vitro by glycosaminoglycans. J Dairy Sci 1993, 76(3):701-712. 
7. Bevers MM, Izadyar F: Role of growth hormone and growth hormone receptor in oocyte maturation. Mol Cell Endocrinol 2002, 197(1-2):173-178.

8. Sun FZ, Moor RM: Nuclear-cytoplasmic interactions during ovine oocyte maturation. Development 1991, 111(1):171-180.

9. Heikinheimo O, Gibbons WE: The molecular mechanisms of oocyte maturation and early embryonic development are unveiling new insights into reproductive medicine. Mol Hum Reprod 1998, 4(8):745-756.

10. Eichenlaub-Ritter $U$, Peschke $M$ : Expression in in-vivo and in-vitro growing and maturing oocytes: focus on regulation of expression at the translational level. Hum Reprod Update 2002, 8(1):21-41.

11. Moor RM, Crosby IM: Protein requirements for germinal vesicle breakdown in ovine oocytes. J Embryol Exp Morphol 1986, 94:207-220.

12. Hunter AG, Moor RM: Stage-dependent effects of inhibiting ribonucleic acids and protein synthesis on meiotic maturation of bovine oocytes in vitro. J Dairy Sci 1987, 70(8):1646-1651.

13. Lonergan P, Monaghan P, Rizos D, Boland MP, Gordon I: Effect of follicle size on bovine oocyte quality and developmental competence following maturation, fertilization, and culture in vitro. Mol Reprod Dev 1994 37(1):48-53.

14. Lequarre AS, Vigneron C, Ribaucour F, Holm P, Donnay I, Dalbies-Tran R, Callesen $\mathrm{H}$, Mermillod P: Influence of antral follicle size on oocyte characteristics and embryo development in the bovine. Theriogenology 2005, 63(3):841-859.

15. van de Leemput EE, Vos PL, Zeinstra EC, Bevers MM, van der Weijden GC, Dieleman SJ: Improved in vitro embryo development using in vivo matured oocytes from heifers superovulated with a controlled preovulatory LH surge. Theriogenology 1999, 52(2):335-349.

16. Leroy JL, Vanholder T, Mateusen B, Christophe A, Opsomer G, de Kruif A Genicot G, Van Soom A: Non-esterified fatty acids in follicular fluid of dairy cows and their effect on developmental capacity of bovine oocytes in vitro. Reproduction 2005, 130(4):485-495.

17. Austin EJ, Mihm M, Ryan MP, Williams DH, Roche JF: Effect of duration of dominance of the ovulatory follicle on onset of estrus and fertility in heifers. J Anim Sci 1999, 77(8):2219-2226.

18. Katz-Jaffe MG, McCallie BR, Preis KA, Filipovits J, Gardner DK: Transcriptome analysis of in vivo and in vitro matured bovine MII oocytes. Theriogenology 2009, 71(6):939-946.

19. Kues WA, Sudheer S, Herrmann D, Carnwath JW, Havlicek V, Besenfelder U, Lehrach $H$, Adjaye J, Niemann H: Genome-wide expression profiling reveals distinct clusters of transcriptional regulation during bovine preimplantation development in vivo. Proc Natl Acad Sci USA 2008, 105(50):19768-19773.

20. Adjaye J, Herwig R, Brink TC, Herrmann D, Greber B, Sudheer S, Groth D, Carnwath JW, Lehrach $\mathrm{H}$, Niemann $\mathrm{H}$ : Conserved molecular portraits of bovine and human blastocysts as a consequence of the transition from maternal to embryonic control of gene expression. Physiol Genomics 2007, 31(2):315-327.

21. Jones GM, Cram DS, Song B, Magli MC, Gianaroli L, Lacham-Kaplan O, Findlay JK, Jenkin G, Trounson AO: Gene expression profiling of human oocytes following in vivo or in vitro maturation. Hum Reprod 2008, 23(5):1138-1144

22. Lee $Y S$, Latham KE, Vandevoort CA: Effects of in vitro maturation on gene expression in rhesus monkey oocytes. Physiol Genomics 2008, 35(2):145-158.

23. Lonergan $P$, Fair T: In vitro-produced bovine embryos: dealing with the warts. Theriogenology 2008, 69(1):17-22.

24. Trounson A, Anderiesz C, Jones G: Maturation of human oocytes in vitro and their developmental competence. Reproduction 2001, 121(1):51-75.

25. Watson AJ: Oocyte cytoplasmic maturation: a key mediator of oocyte and embryo developmental competence. J Anim Sci 2007, 85(13 Suppl): E1-3.

26. Rizos D, Ward F, Duffy P, Boland MP, Lonergan P: Consequences of bovine oocyte maturation, fertilization or early embryo development in vitro versus in vivo: implications for blastocyst yield and blastocyst quality. Mol Reprod Dev 2002, 61(2):234-248.

27. Sirard MA, Richard F, Blondin P, Robert C: Contribution of the oocyte to embryo quality. Theriogenology 2006, 65(1):126-136.

28. Krisher RL: The effect of oocyte quality on development. J Anim Sci 2004, 82(E-Suppl):E14-23.

29. Rijnders PM, Jansen CA: The predictive value of day 3 embryo morphology regarding blastocyst formation, pregnancy and implantation rate after day 5 transfer following in-vitro fertilization or intracytoplasmic sperm injection. Hum Reprod 1998, 13(10):2869-2873.

30. Alper MM, Brinsden P, Fischer R, Wikland M: To blastocyst or not to blastocyst? That is the question. Hum Reprod 2001, 16(4):617-619.

31. Papanikolaou EG, D'Haeseleer E, Verheyen G, Van de Velde H, Camus M, Van Steirteghem A, Devroey P, Tournaye H: Live birth rate is significantly higher after blastocyst transfer than after cleavage-stage embryo transfer when at least four embryos are available on day 3 of embryo culture. A randomized prospective study. Hum Reprod 2005, 20(11):3198-3203.

32. Assou S, Anahory T, Pantesco V, Le Carrour T, Pellestor F, Klein B, Reyftmann L, Dechaud H, De Vos J, Hamamah S: The human cumulusoocyte complex gene-expression profile. Hum Reprod 2006, 21(7):1705-1719.

33. Huarte J, Belin D, Vassalli A, Strickland S, Vassalli JD: Meiotic maturation of mouse oocytes triggers the translation and polyadenylation of dormant tissue-type plasminogen activator mRNA. Genes Dev 1987, 1(10):1201-1211.

34. Pique M, Lopez JM, Mendez R: Cytoplasmic mRNA polyadenylation and translation assays. Methods Mol Biol 2006, 322:183-198.

35. Crozet N: Nulceolar fine structure and RNA synthesis in bovine oocytes from antral follicles. Gamete Research 1986, 14:65-73.

36. Cui XS, Li XY, Yin XJ, Kong IK, Kang JJ, Kim NH: Maternal gene transcription in mouse oocytes: genes implicated in oocyte maturation and fertilization. J Reprod Dev 2007, 53(2):405-418.

37. Thelie A, Papillier P, Perreau C, Uzbekova S, Hennequet-Antier C, Dalbies Tran R: Regulation of bovine oocyte-specific transcripts during in vitro oocyte maturation and after maternal-embryonic transition analyzed using a transcriptomic approach. Mol Reprod Dev 2009, 76(8):773-782.

38. Su YQ, Sugiura K, Woo Y, Wigglesworth K, Kamdar S, Affourtit J, Eppig JJ: Selective degradation of transcripts during meiotic maturation of mouse oocytes. Dev Biol 2007, 302(1):104-117.

39. Elsik CG, Tellam RL, Worley KC, Gibbs RA, Muzny DM, Weinstock GM, Adelson DL, Eichler EE, Elnitski L, Guigo R, et al: The genome sequence of taurine cattle: a window to ruminant biology and evolution. Science 2009, 324(5926):522-528.

40. Downs SM, Eppig JJ: Induction of mouse oocyte maturation in vivo by perturbants of purine metabolism. Biol Reprod 1987, 36(2):431-437.

41. Meinecke $B$, Meinecke-Tillmann S: Effects of alpha-amanitin on nuclear maturation of porcine oocytes in vitro. J Reprod Fertil 1993, 98(1):195-201.

42. Memili E, First NL: Developmental changes in RNA polymerase II in bovine oocytes, early embryos, and effect of alpha-amanitin on embryo development. Mol Reprod Dev 1998, 51(4):381-389.

43. Sriram G, Martinez JA, McCabe ER, Liao JC, Dipple KM: Single-gene disorders: what role could moonlighting enzymes play? Am J Hum Genet 2005, 76(6):911-924.

44. Eppig JJ: Oocyte control of ovarian follicular development and function in mammals. Reproduction 2001, 122(6):829-838.

45. Gilchrist RB, Ritter $L$, Armstrong DT: Oocyte-somatic cell interactions during follicle development in mammals. Anim Reprod Sci 2004, 8283:431-446.

46. Gilchrist RB, Thompson JG: Oocyte maturation: emerging concepts and technologies to improve developmental potential in vitro. Theriogenology 2007, 67(1):6-15

47. Dekel N: Cellular, biochemical and molecular mechanisms regulating oocyte maturation. Mol Cell Endocrinol 2005, 234(1-2):19-25.

48. Tatemoto $H$, Terada $T$ : Time-dependent effects of cycloheximide and alpha-amanitin on meiotic resumption and progression in bovine follicular oocytes. Theriogenology 1995, 43(6):1107-1113.

49. Schmitt A, Nebreda AR: Signalling pathways in oocyte meiotic maturation. J Cell Sci 2002, 115(Pt 12):2457-2459.

50. Chen J, Chi MM, Moley KH, Downs SM: CAMP pulsing of denuded mouse oocytes increases meiotic resumption via activation of AMP-activated protein kinase. Reproduction 2009, 138(5):759-770.

51. Yoshimura Y, Nakamura Y, Oda T, Ando M, Ubukata Y, Karube M, Koyama N, Yamada $\mathrm{H}$ : Induction of meiotic maturation of follicle-enclosed oocytes of rabbits by a transient increase followed by an abrupt decrease in cyclic AMP concentration. J Reprod Fertil 1992, 95(3):803-812.

52. Sanbuissho A, Coskun S, Lin YC: Role of cyclic adenosine monophosphate (cAMP) in vitro on bovine oocyte maturation. Theriogenology 1992, 38(1):153-163 
53. Guixue Z, Luciano AM, Coenen K, Gandolfi F, Sirard MA: The influence of CAMP before or during bovine oocyte maturation on embryonic developmental competence. Theriogenology 2001, 55(8):1733-1743.

54. Lequarre AS, Traverso JM, Marchandise J, Donnay I: Poly(A) RNA is reduced by half during bovine oocyte maturation but increases when meiotic arrest is maintained with CDK inhibitors. Biol Reprod 2004, 71(2):425-431.

55. Leyens G, Verhaeghe B, Landtmeters M, Marchandise J, Knoops B, Donnay I: Peroxiredoxin 6 is upregulated in bovine oocytes and cumulus cells during in vitro maturation: role of intercellular communication. Biol Reprod 2004, 71(5):1646-1651

56. Pocar P, Augustin R, Fischer B: Constitutive expression of CYP1A1 in bovine cumulus oocyte-complexes in vitro: mechanisms and biological implications. Endocrinology 2004, 145(4):1594-1601.

57. Kastrop PM, Hulshof SC, Bevers MM, Destree OH, Kruip TA: The effects of alpha-amanitin and cycloheximide on nuclear progression, protein synthesis, and phosphorylation during bovine oocyte maturation in vitro. Mol Reprod Dev 1991, 28(3):249-254.

58. Stangegaard $M$, Dufva $\mathbb{H}$, Dufva M: Reverse transcription using random pentadecamer primers increases yield and quality of resulting cDNA. Biotechniques 2006, 40(5):649-657.

59. Resuehr D, Spiess AN: A real-time polymerase chain reaction-based evaluation of cDNA synthesis priming methods. Anal Biochem 2003, 322(2):287-291.

60. Ross DM, Watkins DB, Hughes TP, Branford S: Reverse transcription with random pentadecamer primers improves the detection limit of a quantitative PCR assay for BCR-ABL transcripts in chronic myeloid leukemia: implications for defining sensitivity in minimal residual disease. Clin Chem 2008, 54(9):1568-1571.

61. Zhang J, Byrne CD: Differential priming of RNA templates during CDNA synthesis markedly affects both accuracy and reproducibility of quantitative competitive reverse-transcriptase PCR. Biochem J 1999, 337(Pt 2):231-241.

62. Nam DK, Lee S, Zhou G, Cao X, Wang C, Clark T, Chen J, Rowley JD, Wang SM: Oligo(dT) primer generates a high frequency of truncated cDNAs through internal poly(A) priming during reverse transcription. Proc Natl Acad Sci USA 2002, 99(9):6152-6156.

63. Hyttel $P$, Greve T, Callesen H: Ultrastructural aspects of oocyte maturation and fertilization in cattle. J Reprod Fertil Suppl 1989, 38:35-47.

64. Sirard MA, Florman HM, Leibfried-Rutledge ML, Barnes FL, Sims ML, First NL: Timing of nuclear progression and protein synthesis necessary for meiotic maturation of bovine oocytes. Biol Reprod 1989, 40(6):1257-1263.

65. Lonergan P, Khatir H, Carolan C, Mermillod P: Bovine blastocyst production in vitro after inhibition of oocyte meiotic resumption for 24 h. J Reprod Fertil 1997, 109(2):355-365.

66. De Loos FA, Zeinstra E, Bevers MM: Follicular wall maintains meiotic arrest in bovine oocytes cultured in vitro. Mol Reprod Dev 1994, 39(2):162-165.

67. Belloc E, Pique M, Mendez R: Sequential waves of polyadenylation and deadenylation define a translation circuit that drives meiotic progression. Biochem Soc Trans 2008, 36(Pt 4):665-670.

68. Lim LH, Pervaiz S: Annexin 1: the new face of an old molecule. FASEB J 2007, 21(4):968-975.

69. Paciga M, DiMattia GE, Wagner GF: Regulation of luteal cell big stanniocalcin production and secretion. Endocrinology 2004, 145(9):4204-4212.

70. Varghese R, Wong CK, Deol H, Wagner GF, DiMattia GE: Comparative analysis of mammalian stanniocalcin genes. Endocrinology 1998, 139(11):4714-4725

71. Kao WW, Liu CY: Roles of lumican and keratocan on corneal transparency. Glycoconj J 2002, 19(4-5):275-285.

72. Kao WW, Funderburgh JL, Xia Y, Liu CY, Conrad GW: Focus on molecules: lumican. Exp Eye Res 2006, 82(1):3-4.

73. Ying S, Shiraishi A, Kao CW, Converse RL, Funderburgh JL, Swiergiel J, Roth MR, Conrad GW, Kao WW: Characterization and expression of the mouse lumican gene. J Biol Chem 1997, 272(48):30306-30313.

74. Lonergan P, Gutierrez-Adan A, Rizos D, Pintado B, de la Fuente J, Boland MP: Relative messenger RNA abundance in bovine oocytes collected in vitro or in vivo before and $20 \mathrm{hr}$ after the preovulatory luteinizing hormone surge. Mol Reprod Dev 2003, 66(3):297-305.

75. Humblot $P$, Holm P, Lonergan P, Wrenzycki C, Lequarre AS, Joly CG, Herrmann D, Lopes A, Rizos D, Niemann H, et al: Effect of stage of follicular growth during superovulation on developmental competence of bovine oocytes. Theriogenology 2005, 63(4):1149-1166.

76. Bordignon V, Morin N, Durocher J, Bousquet D, Smith LC: GnRH improves the recovery rate and the in vitro developmental competence of oocytes obtained by transvaginal follicular aspiration from superstimulated heifers. Theriogenology 1997, 48(2):291-298.

77. Gentleman RC, Carey VJ, Bates DM, Bolstad B, Dettling M, Dudoit S, Ellis B, Gautier L, Ge Y, Gentry J, et al: Bioconductor: open software development for computational biology and bioinformatics. Genome Biol 2004, 5(10): R80.

78. Hochreiter S, Clevert DA, Obermayer K: A new summarization method for Affymetrix probe level data. Bioinformatics 2006, 22(8):943-949.

79. Talloen W, Clevert DA, Hochreiter S, Amaratunga D, Bijnens L, Kass S, Gohlmann HW: I/NI-calls for the exclusion of non-informative genes: a highly effective filtering tool for microarray data. Bioinformatics 2007, 23(21):2897-2902.

80. Tusher VG, Tibshirani R, Chu G: Significance analysis of microarrays applied to the ionizing radiation response. Proc Natl Acad Sci USA 2001, 98(9):5116-5121.

81. Ashburner M, Ball CA, Blake JA, Botstein D, Butler H, Cherry JM, Davis AP, Dolinski K, Dwight SS, Eppig JT, et al: Gene ontology: tool for the unification of biology. The Gene Ontology Consortium. Nat Genet 2000, 25(1):25-29.

82. Huang da W, Sherman BT, Lempicki RA: Systematic and integrative analysis of large gene lists using DAVID bioinformatics resources. Nat Protoc 2009, 4(1):44-57.

83. Dennis G Jr, Sherman BT, Hosack DA, Yang J, Gao W, Lane HC, Lempicki RA: DAVID: Database for Annotation, Visualization, and Integrated Discovery. Genome Biol 2003, 4(5):P3.

84. Bower NI, Moser RJ, Hill JR, Lehnert SA: Universal reference method for real-time PCR gene expression analysis of preimplantation embryos. Biotechniques 2007, 42(2):199-206.

85. Schmittgen TD, Livak KJ: Analyzing real-time PCR data by the comparative C(T) method. Nat Protoc 2008, 3(6):1101-1108.

doi:10.1186/1471-2164-12-151

Cite this article as: Mamo et al:: Sequential analysis of global gene expression profiles in immature and in vitro matured bovine oocytes: potential molecular markers of oocyte maturation. BMC Genomics 2011 12:151.

\section{Submit your next manuscript to BioMed Central and take full advantage of:}

- Convenient online submission

- Thorough peer review

- No space constraints or color figure charges

- Immediate publication on acceptance

- Inclusion in PubMed, CAS, Scopus and Google Scholar

- Research which is freely available for redistribution

Submit your manuscript at www.biomedcentral.com/submit
C Biomed Central 